\title{
APROVEITAMENTO DO REJEITO DE LAVRA DE ARDÓSIA PARA A PRODUÇÃO DE CARGA MINERAL: POTENCIAL USO EM MATERIAIS COMPÓSITOS *
}

Filipe Mattos Gonçalves ${ }^{1}$ João Walter Meneses Torres ${ }^{2}$ Aline da Luz Pascoal ${ }^{3}$ Eugênio Eustáquio Ferreira ${ }^{4}$ Telma Ellen Drumond Ferreira ${ }^{5}$ Júnia Soares Alexandrino ${ }^{6}$

\section{Resumo}

A exploração da ardósia gera uma grande quantidade de resíduos, principalmente nas fases de extração e de beneficiamento, dando origem a passivos ambientais. No intuito de minimizar esse impacto, este trabalho tem como objetivo aproveitar o rejeito de ardósia para produzir cargas minerais, que são amplamente utilizadas na fabricação de materiais compósitos. Assim, o rejeito de ardósia foi coletado em uma mina próxima a cidade de Pompéu/MG, passou por uma caracterização químicomineralógica e processos de cominuição para adequação da granulometria. Analisando os resultados, foi possível comparar as características dos resíduos de ardósia com outras cargas minerais existentes como o quartzo, pirofilita e muscovita, que já são muito utilizadas no mercado. Desta maneira, este rejeito satisfaz as especificações para ser utilizado como potencial carga em materiais compósitos..

Palavras-chave: Ardósia; Cargas Minerais; Rejeito; Compósitos.

\section{USE OF SLATE WASTE FOR MINERAL FILLER PRODUCTION: POTENTIAL} USE IN COMPOSITE MATERIALS

\section{Abstract}

The exploitation of slate generates a large amount of waste, mainly in the extraction and processing stages, giving rise to environmental liabilities. In order to minimize this impact, this work aims to reuse the slate waste to produce mineral fillers, which are widely used in the manufacture of composite materials. Thus, the slate tailings were collected in a mine near the city of Pompéu / MG, underwent a chemicalmineralogical characterization and comminution processes to adjust the granulometry. Analyzing the results, it was possible to compare the characteristics of slate residues with other existing mineral loads such as quartz, pyrophyllite and muscovite, which are already widely used in the market. In this way, this waste meets the specifications to be used as potential filler in composite materials.

Keywords: Slate; Mineral Fillers; Residues; Composites.

\footnotetext{
Graduando em Engenharia de Minas, UEMG, João Monlevade, Minas Gerais, Brasil. Graduando em Engenharia de Minas, UEMG, João Monlevade, Minas Gerais, Brasil Graduanda em Engenharia de Minas, UEMG, João Monlevade, Minas Gerais, Brasil. Msc, Engenheiro de Minas, Professor, Engenharia de Minas, UEMG, João Monlevade Minas Gerais, Brasil.

5 Msc, Pedagoga, Professora, Engenharia de Minas, UEMG, João Monlevade, Minas Gerais, Brasil. PhD, Química, Professora, Engenharia de Minas, UEMG, João Monlevade, Minas Gerais, Brasil.
} 


\section{INTRODUÇÃO}

A progressiva preocupação com a produção e descarte de resíduos advindos da exploração mineral, principalmente no que tange os fatores econômicos e ao meio ambiente, tem apurado a procura por novos métodos de processamento que ajudem a minimizar este fato. Neste caminho, tem-se a ardósia que é uma das principais rochas ornamentais encontradas no mundo, especialmente em países como Espanha e Brasil, que são grandes exportadores da mesma. No entanto, a exploração da ardósia gera uma grande quantidade de resíduos, criando passivos ambientais.

Minas Gerais, grande estado produtor de ardósia, sofre com os problemas ambientais causados pela extração e beneficiamento dessa rocha. Na região que engloba os municípios produtores é possível encontrar diversas pilhas de rejeito de ardósia dispostas de forma irregular ou sem a devida revegetação imposta por lei. Além disso, pequenas serrarias espalhadas principalmente pelo município de Papagaios despejam o rejeito proveniente do beneficiamento da ardósia em botaforas ilegais ou até mesmo em beiras de estradas e lotes baldios. A população da região já se acostumou a conviver com esse impacto visual, que poderia ser revertido através de estudos de reaproveitamento dos resíduos da ardósia de uma forma sustentável.

Desse modo, uma alternativa para tal situação seria o aproveitamento do rejeito de ardósia proveniente dessa extração para a produção de cargas minerais. As cargas minerais são substâncias não orgânicas compostas por grãos pouco flexíveis que são incorporados à massa de diversos produtos, como por exemplo: polímeros, tintas e sabões, gerando os ditos materiais compósitos (1). As principais cargas utilizadas são a muscovita, quartzo, calcita, dolomita, talco, pirofilita e barita, sendo que, cada tipo de carga possui propriedades e características diferentes, e essas são influenciadas pelo tamanho da partícula, forma, dureza, composição química e estrutura cristalina (2).

No passado, tais cargas eram utilizadas em compósitos apenas como enchimento no intuito de baratear o produto, substituindo algum ingrediente básico. Mas atualmente, as cargas minerais exercem um papel muito mais importante na indústria do que apenas o econômico. Através das novas tecnologias desenvolvidas, as cargas minerais podem, por exemplo, aumentar a resistência à tração, compressão, abrasão e deformação ao calor de um material (2).

Neste sentido, este trabalho objetiva a utilização do rejeito proveniente da lavra de ardósia para a produção de uma potencial carga mineral para ser utilizada em materiais compósitos. Portanto, essa reciclagem de materiais, no caso o rejeito de ardósia, pode contribuir para mitigar um problema ambiental causado pelo descarte inadequado da ardósia no meio ambiente, como também gerar um produto barato que atenderá as especificações das indústrias consumidoras de cargas minerais.

\section{MATERIAIS E MÉTODOS}

As amostras de ardósia utilizadas no experimento foram coletadas em uma mina localizada na cidade de Pompéu - MG. Com o intuito de se obter uma amostra sem contaminantes e saber o ponto de origem exato desse material, o rejeito de ardósia fraturada foi coletado diretamente na frente de lavra. Tal amostra foi encaminhada ao laboratório de Tratamento de Minérios da UEMG - unidade João Monlevade para 
os ensaios de cominuição e classificação. Primeiramente, o rejeito de ardósia (cerca de $6 \mathrm{~kg}$ ) foi fragmentado no britador de mandíbulas modelo BM 120080.

Após essa etapa, o material britado foi quarteado e uma alíquota de $1 \mathrm{~kg}$ foi encaminhada ao moinho de bolas modelo MA 701/21 durante o tempo de uma hora para maior redução de granulometria, objetivando a adequação das cargas minerais utilizadas no Brasil (granulometria abaixo de 45 micrômetros). Em seguida, foi realizada a etapa de classificação do resíduo moído, através do peneiramento a úmido, que segundo Sampaio (3), é mais indicado e eficiente para frações de granulometria fina.

A figura 1 mostra a rota de processo utilizada para a fragmentação e classificação do rejeito de ardósia fraturado, visando a sua adequação dentro das especificações de granulometria para as cargas minerais.

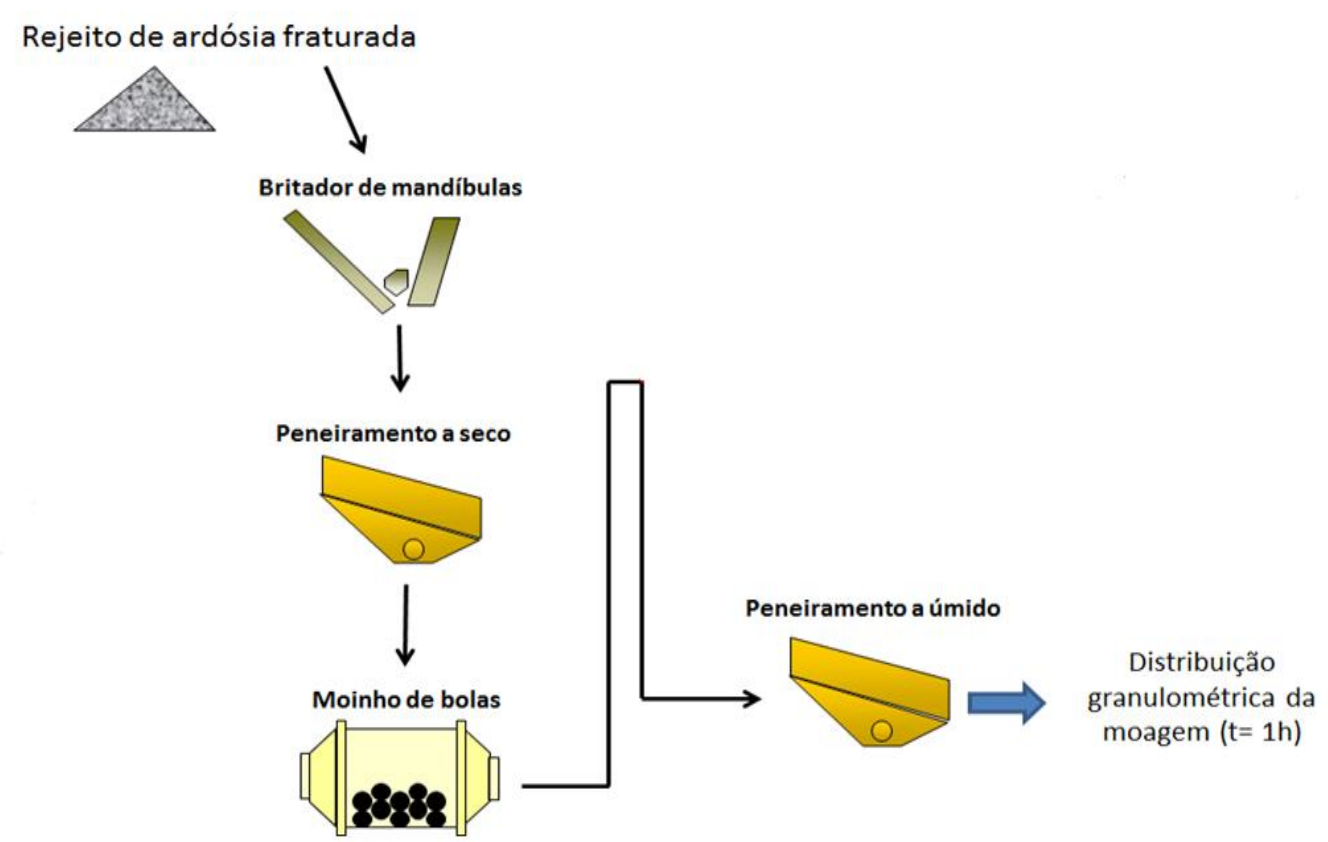

Figura 1. Fluxograma do processo de produção da carga mineral.

Já a caraterização químico-mineralógica foi realizada através da fluorescência de raios $X$. Esta técnica tem sido amplamente utilizada na análise de materiais, sendo em geral um método fácil e confiável, que permite a identificação dos elementos, como também proceder à sua quantificação (4).

Uma alíquota de $350 \mathrm{~g}$ foi enviada para análise em laboratório particular certificado pelas ISO 9001 e ISO 14001 que garantem serviços de qualidade e com respeito ao meio ambiente. Uma vez que alguns elementos químicos como Sílica, Ferro e Alumínio são geralmente encontrados em rochas ardosianas, foi recomendado pelo laboratório que fosse feita a análise para determinar o teor de 10 Óxidos Majoritários determinados por fluorescência de raios $X$.

Por fim, com o auxílio de literatura, as características químicas e físicas do rejeito de ardósia foram comparadas às características e especificações das principais cargas minerais utilizadas em compósitos atualmente. 


\section{RESULTADOS E DISCUSSÃO}

A seguir são relatados os resultados das etapas de fragmentação e classificação para o rejeito de ardósia, de maneira que, o Quadro 1 apresenta a distribuição granulométrica e a Figura 2 mostra o passante acumulado, ambos para o peneiramento a úmido realizado após a etapa de moagem.

Quadro 1. Distribuição granulométrica do peneiramento a úmido para a etapa de moagem

\begin{tabular}{|c|c|c|c|c|c|}
\hline \multicolumn{5}{|c|}{ Faixa granulométrica } & \multicolumn{3}{c|}{ Massa inicial = 100g } \\
\hline MALHAS & ABERTURAS & Peso(g) & \% Retido & \%Retido acumulado & \% Passante \\
\hline Tyler & $(\mathrm{mm})$ & $\mathrm{t}=1 \mathrm{~h}$ & $\mathrm{t}=1 \mathrm{~h}$ & $\mathrm{t}=1 \mathrm{~h}$ & $\mathrm{t}=1 \mathrm{~h}$ \\
\hline & & & & & \\
\hline & & & & & \\
\hline 35 & 0,425 & 18,4 & 18,40 & 18,40 & 81,6 \\
\hline 60 & 0,25 & 0,1 & 0,10 & 18,50 & 81,5 \\
\hline 100 & 0,15 & 0,5 & 0,50 & 19,00 & 81,0 \\
\hline 140 & 0,106 & 0,9 & 0,90 & 19,90 & 80,1 \\
\hline 200 & 0,074 & 1,9 & 1,90 & 21,80 & 78,2 \\
\hline 270 & 0,053 & 1,5 & 1,50 & 23,30 & 76,7 \\
\hline 325 & 0,045 & 3,6 & 3,60 & 26,90 & 73,1 \\
\hline Fundo & $-0,045$ & 73,1 & 73,10 & 100,00 & 0,0 \\
\hline & & & & & \\
\hline Total (g) & & 100 & & & \\
\hline Perda (g) & & 0 & & & \\
\hline
\end{tabular}

Para efeito de classificação, através do Quadro 1 plotou-se o gráfico (Figura 2) em escala logarítmica no eixo das abcissas, no intuito de representar o passante acumulado em função da abertura das peneiras. Dessa forma, com base os dados apresentados, $81 \%$ da amostra é considerada ultrafina (menor que $0,15 \mathrm{~mm}$ ), pois passou na abertura de $0,15 \mathrm{~mm}$, e os outros $19 \%$ da amostra é considerada fina (entre $6,35 \mathrm{~mm}$ e $0,15 \mathrm{~mm}$ ), pois as partículas ficaram retidas nas peneiras de $0,60 \mathrm{~mm}$ e $0,15 \mathrm{~mm}$.

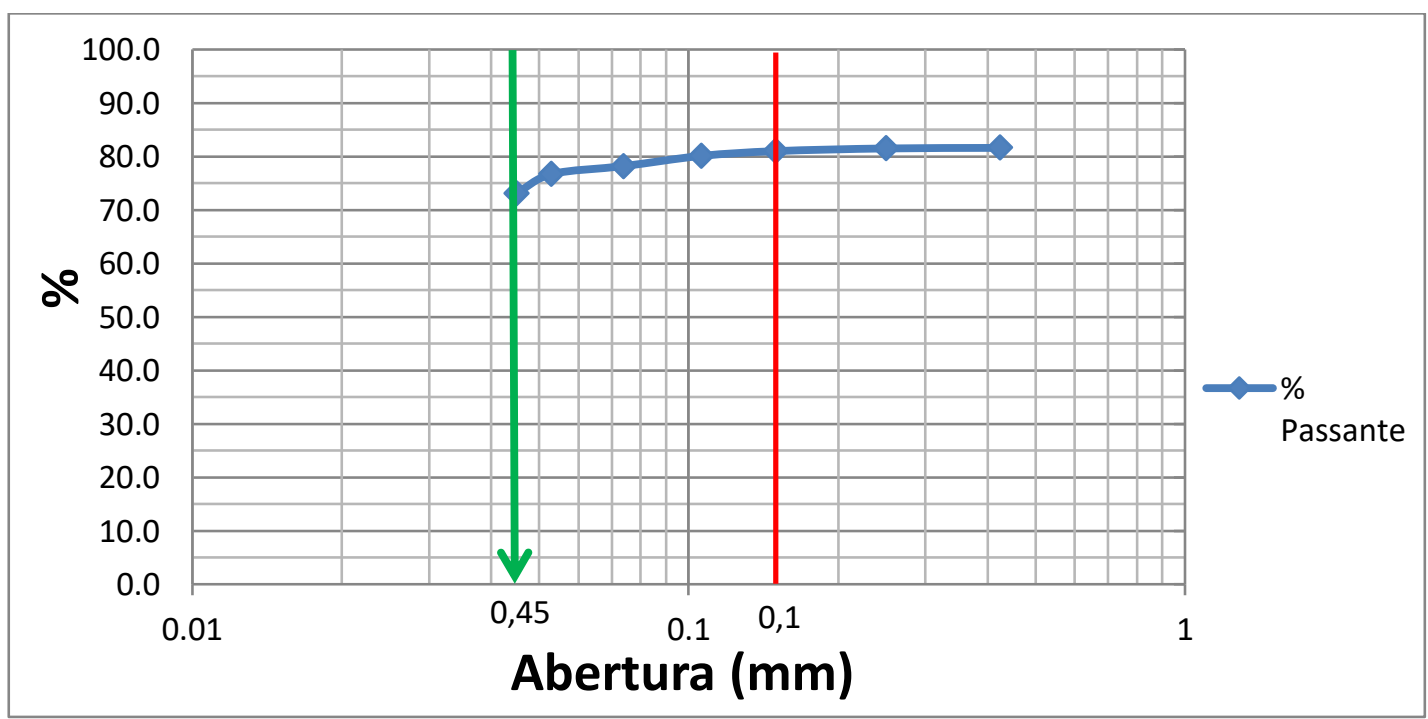

Figura 2. Gráfico passante acumulado do peneiramento a úmido para a etapa de moagem. 
Vale a pena ressaltar que aproximadamente $73 \%$ da amostra de rejeito de ardósia passou na peneira de $0,045 \mathrm{~mm}$, representando a eficiência da moagem e do peneiramento a úmido, bem como mostrando que o material se enquadrou na especificação de granulometria da cargas minerais, que no Brasil devem estar abaixo de $45 \mu \mathrm{m}$.

Já no que diz respeito as características químicas e mineralógicas do rejeito de ardósia fraturado, abaixo tem-se os resultados da fluorescência de raios X abaixo (Quadro 2).

Quadro 2. Caracterização químico-mineralógica para o rejeito de ardósia fraturado.

\begin{tabular}{|c|c|c|c|c|c|c|c|c|c|}
\hline \multicolumn{10}{|c|}{ Análise químico-mineralógica } \\
\hline Óxidos & $\mathrm{SiO2}$ & $\mathrm{Al} 2 \mathrm{O} 3$ & $\mathrm{FeO} 3$ & $\mathrm{CaO}$ & $\mathrm{MgO}$ & $\mathrm{TiO} 2$ & $\mathrm{P} 2 \mathrm{O} 5$ & $\mathrm{Na} 2 \mathrm{O}$ & $\mathrm{K} 2 \mathrm{O}$ \\
\hline & & & & & & & & & \\
\hline Branco (\%) & $>99$ & $<0,1$ & 1,48 & 0,01 & $<0,1$ & $<0,01$ & $<0,01$ & $<0,1$ & $<0,01$ \\
\hline Rejeito de ardósia (\%) & 60,6 & 16,7 & 7,23 & 2,16 & 3,54 & 0,74 & 0,17 & 1,74 & 3,81 \\
\hline
\end{tabular}

Conforme esperado, as análises químicas revelaram altos teores de Sílica, Alumínio e Ferro para amostra de ardósia fraturada. Além desses elementos químicos, também foram revelados teores consideráveis de Cálcio, Magnésio e Potássio.

Quando comparado os teores dos elementos químicos presentes nos resíduos de rochas ardosianas com os teores presentes nos principais minerais utilizados como carga mineral, pode-se inferir que o mesmo tem capacidade em ser utilizada como cargas por apresentar composição similar a esses minerais. O Quadro 3 apresenta a composição química dos principais minerais utilizados como carga mineral.

Quadro 3. Composição química dos principais minerais utilizados como carga mineral (Adaptado de Lima, 2007).

\begin{tabular}{|c|c|c|c|c|c|c|c|c|c|c|}
\hline & Talco & Pirofilita & Caulinita & Esmectita & Muscovita & Calcita & Dolomita & Quartzo & Wolastonita & Barita \\
\hline Fórmula química & $\begin{array}{l}\mathrm{Mg}_{6}\left(\mathrm{Si}_{8} \mathrm{O}_{20}\right) \\
(\mathrm{OH})_{4}\end{array}$ & $\begin{array}{l}\left(\mathrm{Si}_{4} \mathrm{O}_{10}\right) \\
\mathrm{Al}_{2}(\mathrm{OH})_{2}\end{array}$ & $\mathrm{Al}_{2} \mathrm{Si}_{2} \mathrm{O}_{5}(\mathrm{OH})_{4}$ & $\begin{array}{l}(\mathrm{Mg}, \mathrm{Ca}) \mathrm{O} \\
\mathrm{Al}_{2} \mathrm{O}_{3} \mathrm{Si}_{5} \mathrm{O}_{10} \\
\mathrm{nH}_{2} \mathrm{O}\end{array}$ & $\begin{array}{l}\mathrm{K} \mathrm{Al}_{2} \mathrm{Si}_{3} \mathrm{AlO}_{10} \\
(\mathrm{OH}, \mathrm{F})_{2}\end{array}$ & $\mathrm{CaCO}_{3}$ & $\mathrm{CaMg}\left(\mathrm{CO}_{3}\right)_{2}$ & $\mathrm{SiO}_{2}$ & $\mathrm{CaSiO}_{3}$ & $\mathrm{BaSO}_{4}$ \\
\hline Composição & $\begin{array}{l}31,8 \mathrm{MgO} \\
63,3 \mathrm{SiO}_{2} \\
4,7 \mathrm{H}_{2} \mathrm{O}\end{array}$ & $\mid \begin{array}{l}28,3 \% \mathrm{Al}_{2} \mathrm{O}_{3}, \\
66,7 \% \mathrm{SiO}_{2}, \\
5,0 \% \mathrm{H}_{2} \mathrm{O}\end{array}$ & $\begin{array}{l}39,5 \% \mathrm{Al}_{2} \mathrm{O}_{3}, \\
46,5 \% \mathrm{SiO}_{2}, \\
14 \% \mathrm{H}_{2} \mathrm{O}\end{array}$ & $\begin{array}{l}0,6 \mathrm{~K}_{2} \mathrm{O} \\
2,3 \mathrm{Na}_{2} \mathrm{O} \\
2,1 \mathrm{CaO} \mathrm{O} \\
39,0 \mathrm{Al}_{2} \mathrm{O}_{3} \\
45,9 \mathrm{SiO}_{2} \\
9,1 \mathrm{H}_{2} \mathrm{O}\end{array}$ & $\begin{array}{l}11,8 \% \mathrm{~K}_{2} \mathrm{O}, \\
38,3 \% \mathrm{Al}_{2} \mathrm{O}_{3}, \\
45,2 \% \mathrm{SiO}_{2}, \\
4,2 \% \mathrm{H}_{2} \mathrm{O}\end{array}$ & $\begin{array}{l}53,0 \% \mathrm{CaO}, \\
44,0 \% \mathrm{CO}_{2}\end{array}$ & $\begin{array}{l}30,4 \% \mathrm{CaO}, \\
21,7 \% \mathrm{MgO}, \\
47,7 \% \mathrm{CO}_{2}\end{array}$ & $\begin{array}{l}46,7 \% \mathrm{Si}, \\
53,2 \% 0\end{array}$ & $\begin{array}{l}48,2 \% \mathrm{CaO}, \\
51,7 \% \mathrm{SiO}_{2}\end{array}$ & $\begin{array}{l}34,4 \% \mathrm{SO}_{3}, \\
65,7 \% \mathrm{BaO}\end{array}$ \\
\hline
\end{tabular}

Minerais como Pirofilita, Caulinita, Muscovita, Quartzo e Talco também contém a Sílica como principal elemento químico presente em sua composição. Além disso, a maioria desses minerais também apresentam Alumínio, Cálcio e Magnésio em sua composição química. Tais fatores reforçam o potencial que o rejeito de ardósia possui para ser usado como carga mineral em compósitos, uma vez que sua composição química é muito similar aos minerais já utilizados para essa finalidade. 


\section{CONCLUSÃO}

No Brasil, os órgãos de fiscalização ambiental e mineral ainda falham no sentido de supervisionar e controlar o grande número de minas e processos industriais existentes. Esse fato faz com que a maioria dos resíduos provenientes da extração e beneficiamento da ardósia sejam dispostos em áreas inadequadas e de maneira irregular, gerando um passivo ambiental. Dessa forma, é de extrema importância destinar este material para um aproveitamento adequado. O emprego do rejeito de ardósia contribui para evitar gastos com o seu descarte, além de reduzir o impacto ambiental causado pela disposição inadequada desse material.

Com base nos resultados obtidos, pode-se perceber que o material ultrafino proveniente da cominuição do rejeito de ardósia fraturada, mostrou-se tecnicamente viável como carga mineral para uso em materiais compósitos, atendendo as especificações físicas e químicas necessárias para a produção do mesmo, atigindo os objetivos propostos pelo trabalho.

É importante ressaltar que devem ser realizadas aplicações experimentais do rejeito de ardósia em produtos que utilizam carga mineral como matéria-prima, no intuito de conhecer melhor essa interação e analisar as propriedades mecânicas dos compósitos produzidos.

\section{REFERÊNCIAS}

1 Rothon, R. Particulate filled polymer composites. Longman Scientific and Technical. London; 1995.

2 Lima, ABT. Aplicações de cargas minerais em polímeros. Dissertação de Mestrado, Departamento de Engenharia de Minas e de Petróleo, Universidade de São Paulo, São Paulo. 2007.

3 Sampaio, JA. Tratamento de minérios: Práticas laboratoriais. $3^{\circ}$ Ed. Rio de Janeiro: CETEM - Centro de Tecnologia Mineral; 2007.

4 Barbosa, MIM. Bertolino, LC. Tratamento de Minérios: Caracterização Mineralógica de Minérios Parte I. 5ํ Ed. Rio de Janeiro: CETEM - Centro de Tecnologia Mineral; 2010. 